\title{
APLIKASI SISTEM MONITORING KEADAAN KOMPUTER DI LABORATORIUM PADA PERGURUAN TINGGI RAHARJA
}

\author{
Sugeng Santoso ${ }^{1}$ \\ Diki Arif Rahman ${ }^{2}$ \\ Diar Eka Purnama ${ }^{3}$ \\ Jl. Jendral Sudirman No. 40, Modernland, Tangerang \\ Email :sugeng.santoso@raharja.info,dikiarif@raharja.info,diar.eka@raharja.info
}

\begin{abstract}
ABSTRAK
Banyaknya pengguna komputer yang kurang memiliki pengetahuan yang cukup terhadap penanganan kerusakan hardware mengakibatkan banyak sekali pengguna komputer atau suatu institusi yang mengeluarkan biaya yang tidak sedikit hanya untuk memperbaiki kerusakan yang terjadi pada hardware komputer. Oleh sebab itu aplikasi sistem monitoring kerusakan komputer Lab pada Perguruan Tinggi Raharja ini dibuat untuk membantu memantau pengguna komputer tersebut dalam melakukan pendeteksian kerusakan pada hardware komputer yang beserta solusi untuk mengatasi kerusakan tersebut. Dengan adanya permasalah dalam kerusakan komputer Lab di Perguruan Tinggi Raharja setiap Laboratorium terdiri dari 4 Laboratorium masing-masing komputer Laboratorium setiap kelasnya ada 40 unit komputer dan total keseluruhan komputer Laboratorium ada 160 unit komputer. Sistem yang berjalan saat ini masih menggunakan sistem pemeriksaan manual dengan menggunakan media ceklist kerusakan komputer Lab. Untuk itu dalam meningkatkan pelayanan maintenance di Lab sebaiknya harus dikembangkan sebuah sistem aplikasi yang mendukung dalam ketepatan dan keakuratan dalam maintenance Lab sehingga dapat membantu teknisi dalam monitoring lab baik software maupun Hardware.
\end{abstract}

Kata Kunci: Monitoring, Maintenance komputer, Aplikasi komputer

\begin{abstract}
The number of computer users who lack sufficient knowledge of the handling hardware damage caused so many users computer or an institution to issue only a small cost to repair the damage done to computer hardware. Therefore, application monitoring system computer malfunction on Higher Education Prog Lab was created to help monitor the computer users in the detection of damage to computer hardware and solutions to overcome such defects. With the problems in damage to the computer lab at the College of Laboratory Prog each consisting of four laboratories each computer laboratories each class there are 40 computers and computer laboratories total there are 160 units of computers. The current system is still using manual inspection system using a computer malfunction checklist media laboratories. To raise their maintenance services in the Lab should be developed an application system that supports the precision and accuracy in the lab so that maintenance can help lab technicians in monitoring both software and hardware.
\end{abstract}

Keywords: Monitoring, Computer Maintenance, Computer Applications

Vol.2 No.2 - Agustus 2016 


\section{PENDAHULUAN}

Dengan semakin pesatnya perkembangan teknologi informasi saat ini diperlukan kecepatan, ketepatan, serta keakuratan dalam mendapatkan informasi, sehingga semua orang dapat menerima informasi secara up to date tanpa menunggu waktu yang lama untuk mendapat informasi tersebut. Informasi akan sangat berharga sekali nilainya apabila informasi itu dapat memberikan manfaat bagi yang membutuhkannya, mulai dari perusahaan swasta, instansi pemerintahan, dunia pendidikan, bahkan sampai kepelosok desa saat ini sudah banyak menggunakan teknologi informasi. Perguruan Tinggi Raharja adalah kampus yang bergerak dibidang informatika yang mempunyai Lab Digital dan Teori, menyediakan peminjaman barang alat elektronik dan alat jaringan komputer. Sistem monitoring pada lab Digital dan Teori belum mempunyai manajemen yang baik atau masih secara manual sehingga Perguruan Tinggi Raharja sering mengalami kerusakan pada komputer. Didalam pelaksanaan perbaikan komputer lab tersebut beberapa permasalahan yang dihadapi dan timbul dalam perancangan sistem kerusakan Lab Digital dan Teori pada Perguruan Tinggi Raharja dalam perbaikkan barang alat komputer di antaranya banyak barang yang rusak dan hilang berakibat dapat merugikan Perguruan Tinggi Raharja karena harganya yang mahal dan tidak digantikan oleh kampus. Kerusakan barang dan kehilangan merupakan salah satu faktor penting yang mengarah ke pada menurunya tingkat keuntungan. Mahasiswa/i ada beberapa komputer yang tidak bisa digunakan karena ada beberapa yang tidak berfungsi. Selaku asisten labotarium masih mengerjakan manual mengecek komputer labotarium, kesulitan tersebut berdampak memperlamabat jam perkerjaan pada asisten labotarium perguruan tinggi raharja.

\section{PERMASALAHAN}

Berdasarkan latar belakang masalah di atas, maka dirumuskan beberapa masalah, yaitu :

a) Apakah sistem yang ada sudah dapat memberikan laporan kerusakan lab secara cepat dan akurat?

b) Apakah sistem dengan media deteksi LAN pada komputer lab sudah optimal ?

c) bagai mana membuat rancangan sistem aplikasi yang terpusat dalam server (localhost) pada Perguruan Tinggi Raharja?

\section{LITERATUR REVIEW}

Banyak penelitian yang sebelumnya dilakukan mengenai Sistem Monitoring Kerusakan labotarium Komputer. Dalam upaya pengembangannya perlu dilakukan studi pustaka sebagai salah satu dari penerapan metode penelitian yang akan dilakukan. Diantaranya adalah Pengumpulan Data ( Observasi Research), Wawancara (Interview Research) ,dan Studi Pustaka ( Library Research) mengidentifikasikan metode yang pernah dilakukan, meneruskan penelitian sebelumnya, serta mengetahui orang lain yang spesialisasi dan area penelitiannya sama dibidang ini. Beberapa Literature review tersebut adalah sebagai berikut :

1. Tinjauan studi dari penelitian Rahmad Hidayat, ST dan Minarni, S. Si., M.T, 2013, Institut Teknologi Padang, dalam Jurnal TEKNOIF Vol.1/No.1, Edisi April 2013 [Hidayat dan Minarni 2013] dalam Jurnal TEKNOIF Vol.1/No.1, berjudul "RANCANG BANGUN APLIKASI SISTEM PAKAR UNTUK KERUSAKAN KOMPUTER DENGAN METODE BACKWARD CHAINING". Penelitian ini bertujuan untuk mengetahui kerusakan komputer dalam pengembangan sistem pakar

Vol.2 No.2 - Agustus 2016 
untuk kerusakan komputer dengan metode backward chaining dan alat bantu Visual Basic 6.0 dimana nantinya dapat memberikan informasi bagi pengguna komputer yang mengalami permasalahan komputer. Agar lebih mudah komputer ini pelacakan mesin inferensinya adalah pelacakan mundur (backward chaining) yang dimulai dari sekumpulan hipotesis gejala kerusakan menuju fakta-fakta yang mendukung hipotesis tersebut. Hasil perancangan akan memberikan informasi kepada pemakai komputer bagaimana mengenali erorr pada aplikasi yang terpasang di komputer serta memberikan solusi kepada pengguna terhadap permasalahan yang dialami.[4]

2. Tinjauan studi dari penelitian Abid Yanuar Badharudin dan Dwi Aryanto, 2011, Universitas Muhammadiyah Purwokerto, JUITA ISSN: 2086-9398 Vol.1 Nomor 4, Edisi November 2011

[Yanuar dan aryanto 2011] dalam Jurnal JUITA ISSN: 2086-9398 Vol.I No.4 berjudul "APLIKASI SISTEM PAKAR UNTUK MENDIAGNOSA KERUSAKAN MONITOR CRT (CATHODE RAY TUBE)". Penelitian ini bertujuan untuk mengetahui kerusakan monitor CRT (cathode ray tube) pada perangkat layar monitor pengguna komputer, apa yang harus dilakukan jika mengalami kendala kerusakan pada layar monitor komputernya. Turing adalah merupakan pengembangan dari mesian hitung konfensional, yang bertujuan sebagai alat bantu bagi manusia. Bahkan komputer pada saat ini juga turut berperan dalam pemberian keputusan. Mengetahuin bagaimana program sudah sesuai dengan yang diharapkan atau belum. Bila terdapat kesalahan (error), maka program harus diperbaiki sesuai dengan kesalahannya. Dengan aplikasi ini pengguna bisa berkonsultasi bagaimana masalah kerusakan monitor CRT dan bisa memberikan solusi pemecahannya. Dengan pengolahan data yang sederhana (Forward Chaining). Runut maju yaitu menggunakan himpunan aturan kondisi-aksi. Dalam metode ini data digunakan untuk menentukan aturan mana yang dijalankan, kemudian aturan tersebut dijalankan, memungkinkan penambahan data ke memori kerja.[9]

3. Tinjauan studi dari penelitian Muhammad Dahria, 2012, STMIK Triguna Dharma, Jurnal ilmiah SAINTIKOM Vol. 11 / No. 1 / Januari 2012

[Dahria 2012] dalam Jurnal ilmiah berjudul "IMPLEMENTASI BACKWARD CHAINING UNTUK MENGETAHUI KERUSAKAN MONITOR KOMPUTER" penelitian ini bertujuan implementasi menggunakan inferensi backward chaining akan memberikan output berupa solusi dari suatu masalah berdasarkan kumpulan pengetahuan yang ada dalam knowledge base yang bisa mengetahui kerusakan monitor komputer. Fakta tentang aturan kategori, jenis dan ciri kerusakan komputer diperoleh dari database dan pengguna sistem memilih komponen komputer yang bermaslah dengan memasukkan jenis dan ciri kerusakan pada interface (antarmuka) pengguna. Kesimpulannya Perangkat lunak yang dirancang dengan rule-based expert system digunakan untuk mengetahui kerusakan monitor komputer Sehingga dapat membantu para teknisi komputer dalam mengatasi masalah-masalah yang berkaitaan dengan kerusakan monitor komputer dan sekaligus memberikan solusi pemecahan masalah secara tepat dan cepat.[2] 


\section{PEMBAHASAN}

\section{Teori Pendukung \\ Definisi Sistem}

Sebuah sistem yang tepat guna akan memberikan dampak yang positif bagi suatu perusahaan dalam pencapaian sasaran serta tujuan perusahaan. sistem terdapat beberapa pandangan menurut para ahli, diantaranya :

Pengertian sistem yang dapat didefinisikan dengan pendekatan prosedur yaitu kumpulan dari prosedur - prosedur yang mempunyai tujuan tertentu. Sistem juga dapat di definisikan dengan pendekatan komponen yaitu kumpulan dari komponen yang saling berhubungan satu dengan yang lainnya membentuk satu kesatuan untuk mencapai tujuan tertentu.[1]

Secara umum, definisi sistem adalah kumpulan bagian-bagian atau subsistem-subsistem yang disatukan dan dirancang untuk mencapai suatu tujuan tertentu.

\section{Karakteristik Sistem}

Suatu sistem mempunyai karakteristik atau sifat - sifat tertentu antara lain :[8]

1. Komponen Sistem (components)

Suatu sistem harus terdiri dari sejumlah komponen yang saling berinteraksi, artinya saling bekerja sama membentuk satu kesatuan. Komponen sistem dapat berupa subsistem-subsistem atau bagian-bagian sistem.

2. Batasan Sistem (boundary)

Batasan sistem (boundary) merupakan daerah yang membatasi antara suatu sistem dengan sistem yang lainnya atau dengan lingkungan luarnya.Batasan sistem ini memungkinkan suatu sistem dipandang sebagai satu kesatuan, batasan sistem menunjukan ruang lingkup (scope) sistem itu sendiri.

3. Lingkungan Luar (environments)

Lingkungan luar sistem (environments) yaitu apapun di luar batas sistem yang dapat mempengaruhi operasi sistem.Lingkungan luar sistem dapat bersifat menguntungkan dan dapat juga bersifat merugikan.Lingkungan luar sistem yang menguntungkan merupakan energi dari sistem tersebut dengan demikian harus tetap dijaga dan dipelihara.Lingkungan luar sistem yang merugikan harus ditahan dan dikendalikan.

4. Penghubung (interface)

Penghubung sistem (interface) merupakan media penghubung antara satu subsistem dengan subsistem yang lainnya.Melalui penghubung ini memungkinkan sumber daya mengalir dari subsistem yang satu ke subsistem yang lainnya.

5. Tujuan atau Sasaran (goals)

Suatu system dikatakan berhasil bila mengenai tujuannya. Kalau suatu sistem tidak mempunyai tujuannya, maka operasi sistem tidak ada gunanya.

\section{Syarat-Syarat Sistem}

Syarat-syarat yang harus dimiliki oleh suatu sistem, yaitu:[3]

1. Sistem harus dibentuk untuk menyelesaikan suatu tujuan.

2. Elemen sistem harus mempunyai rencana yang ditetapkan.

3. Adanya hubungan diantara elemen sistem.

Vol.2 No.2 - Agustus 2016 
4. Unsur dasar dari proses (arus informasi, energi, dan material) lebih penting daripada elemen sistem.

\section{Klasifikasi Sistem}

Sistem merupakan suatu bentuk integrasi antara sutu komponen dengan komponen lainnya karena sistem memiliki sasaran yang berbeda untuk setiap kasus yang terjadi yang ada didalam sistem tersebut.

\section{Konsep Dasar Prototype}

Salah satu fungsi dasar prototype adalah sebagai "proof of concept", jadi ia disusun ketika sudah ada konsep yang perlu kita tes atau uji coba. sebuah konsep layak dijadikan prototype ketika konsep itu sudah memiliki tema atau latar cerita. Prototype adalah bagian sebuah produk yang mengekspresikan logika maupun fisik antarmuka eksternal yang ditampilkan dan perubahan cepat dalam pembangunan prototye.[6]

\section{Jenis-Jenis Protoype}

\section{Rapid Throwaway Prototype}

Pendekatan pengembangan dari perangkat lunak/keras yang ini dipopulerkan oleh Gomaa dan Scoot (1981) yang sekarang ini telah digunakan secara lebih luas oleh industriindustri, terutama di dalam pengembangan sebuah aplikasi.

\section{Prototype Evolusioner}

Dalam pendekatan prototype evolusioner, sebuah prototype itu didasarkan dari kebutuhan dan pemahaman secara umum. Prototype kemudian diubah dan juga dievolusikan daripada dibuang. Prototype yang dibuang biasanya digunakan dari aspek sistem yang dimengerti secara luas dengan dibangun diatas dasar kekuatan tim pengembang.

\section{Pengertian Monitoring}

Monitoring adalah pemantauan yang dapat dijelaskan sebagai kesadaran (awareness) tentang apa yang ingin diketahui, pemantauan berkadar tingkat tinggi dilakukan agar dapat membuat pengukuran melalui waktu yang menunjukkan pegerakan kea rah tujuan atau menjauh dari itu. Monitoring akan memberikan informasi tentang status dan kecenderungan bahwa pengukuran dan evaluasi yang diselesaikan berulang dari waktu ke waktu, pemantauan umumnya dilakukan untuk tujuan tertentu, untuk memeriksa terhadap proses berikut objek atau untuk mengevaluasi kondisi atau kemajuan menuju tujuan hasil menajemen atas efek tindakan dari beberapa jenis antara lain tindakan untuk mempertahankan manajemen yang sedang berjalan.[5]

\section{Laboratorium}

Pengertian Laboratorium adalah tempat riset ilmiah, eksperimen, pengukuran ataupun pelatihan ilmiah yang berhubungan dengan kegiatan-kegiatan tersebut secara terkendali Senada dengan pengertian diatas Laboratorium adalah unit penunjang akademik berupa ruangan tertutup atau terbuka yang permanen atau bergerak, yang dikelola secara sistematis untuk kegiatan pengujian, pembelajaran, kalibrasi, dan atau produksi (dalam skala terbatas) menggunakan bahan dan peralatan berdasarkan metode keilmuan tertentu dalam rangka kegiatan pendidikan, penelitian, dan/atau ilmu komputer dan memiliki

Vol.2 No.2 - Agustus 2016 
beberapa komputer dalam sutu jaringan untuk penggunaan oleh mahasiswa/i pada Peguruan Tinggi Raharja.[7]

\section{Kerusakan Komputer}

Kerusakan komputer adalah memliki banyak masalah dalam menunjang performancenya tapi terkadang komputer itu sendiri mempunyai masalah atau gangguan dalam pengoperasiannya dan untuk dapat memperbaiki komputer, terlebih harus bisa mendeteksi penyebab kerusakan tersebut. Kerusakan pada komputer dapat dibagi dua, yaitu :

1. Faktor perangkat Keras (Hardware)

Biasanya disebabkan karena instalasi hardware belum seperti pemasangan kabel, jumper, slot, baut, atau skrup dan kerusakan pada komponen hardware seperti processor, Motherbord, Memory, VGA card atau hardisk dan lain-lain.

2. Faktor Perangkat Lunak (software)

Kerusakan faktor perangkat Lunak karena kerusakan pada Sistem Operasi, kerusakan aplikasi dan kerusakan pada Driver.

\section{Implementasi}

Dalam metode perancangan digunakan metode berorientasi objek, Unified Modeling Language (UML) dengan menggunakan tool Visual Paradigm 6.4. PHP sebagai scriptnya $M y S Q l$ untuk databasenya serta Macromedia Dreamweaver 8 untuk membuat rancangan program.

\section{Use Case Diagram Sistem Yang di Usulkan Menggunakan UML}

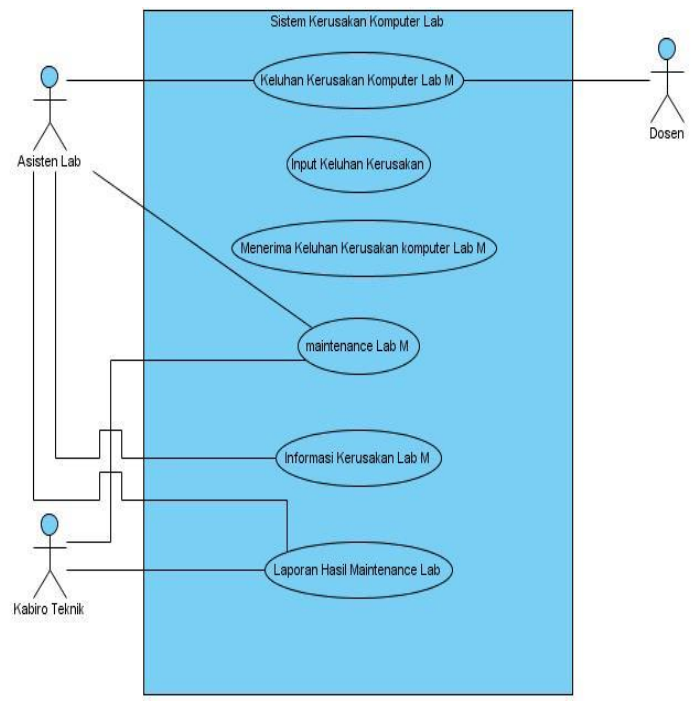

Gambar 1. Use Case Diagram Sistem Pemeliharaan Perangkat IT Hardware.

a. 1 sistem yang mencakup seluruh pengolahan data.

b. 3 actor yang melakukan kegiatan yaitu: Asisten Lab, Kabiro Teknik, Dosen.

Vol.2 No.2 - Agustus 2016 
c. 6 use case yang dilakukan diantaranya: Keluhan Kerusakan komputer Lab, Input Keluhan Kerusakan, Menerima Keluhan Kerusakan Komputer Lab, Maintenance Lab, Informasi Kerusakan Lab, Laporan Hasil Maintenance Lab.

\section{Sequence Diagram yang di Usulkan}

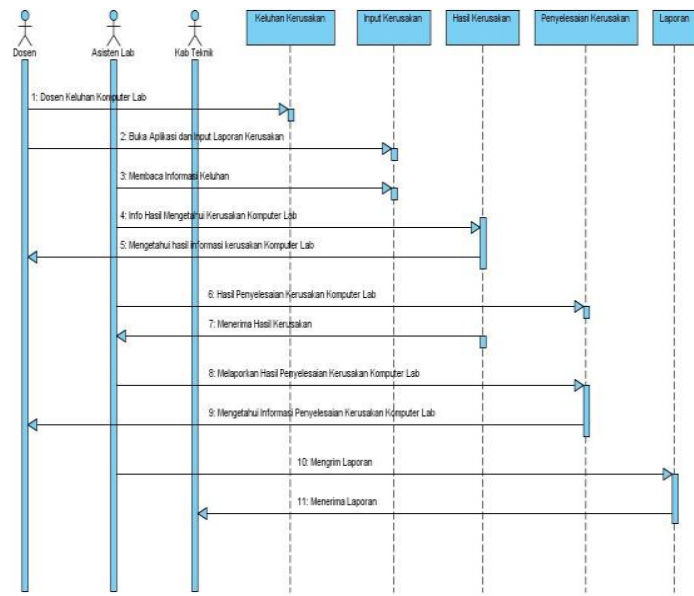

Gambar 2. Squence Diagram Sistem

Pemeliharaan Perangkat IT Hardware.

a. 3 actor yang melakukan kegiatan yaitu: Asisten Lab, Kabiro Teknik, Dosen.

b. 5 Lifeline objek entity antar muka yang saling beirnteraksi yaitu terdiri dari Keluhan Kerusakan, Input Keluhan, Hasil Kerusakan, Penyelesaian Kerusakan, Laporan.

c. 11 Message, yang memuat informasi-informasi tentang aktifitas yang dapat dilakukan oleh actor tersebut.

\section{Activity Diagram Sistem Yang Berjalan}

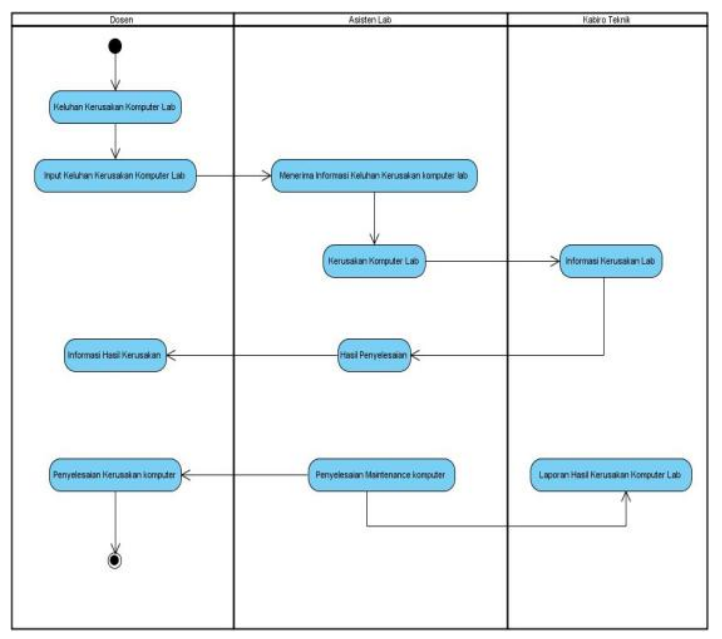

Gambar 3. Activity Diagram Sistem Pemeliharaan Perangkat IT hardware.

a. 1 initial node yang merupakan mengawali kegiatan.

Vol.2 No.2 - Agustus 2016 
b. 3 Swimlame yaitu Asisten Lab, Kabiro Teknik, Dosen.

c. 10 action, state dari sistem yang mencerminkan eksekusi suatu aksi, yaitu Keluhan Kerusakan Komputer Lab, Input Keluhan Kerusakan Komputer Lab, Menerima Informasi Keluhan Kerusakan komputer Lab, Maintenance Kerusakan Komputer Lab, Informasi Kerusakan Lab, Hasil Penyelesaian, Informasi Hasil Maintenance Kerusakan, Laporan hasil kerusakan komputer Lab, Penyelesaian Maintenance komputer, Penyelesaian Kerusakan.

d. 1 final node yang merupakan akhir kegiatan.

\section{Rancangan struktur database}

Rancangan database digunakan sebagai media penyimpanan data yang dipergunakan dalam aplikasi ini dan database membantu pemrograman dalam menampilkan data. Pada tabel ini akan dijelaskan nama field, lebar, dan keterangan mengenai database tersebut.



Gambar 4. Class Diagram yang diusulkan Terdapat :

a. 5 class, himpunan dari objek-objek yang berbagi atribut serta operasi yang sama diantaranya : Asisten Lab, Dosen, Pesan, Laboratorium, Laporan

b. 5 Association, hubungan antara objek satu dengan objek lainnya yang mempunyai nilai.

\section{Analisa Masalah Sistem}

Masalah yang dihadapi pada sistem yang berjalan adalah sebagai berikut :

1. Pada saat pemeriksaan kerusakan komputer lab masih memeriksa dengan manual dan pada saat memeriksaan masih melihat komputer satu - satu mana yang rusak dan mana yang masih bagus untuk digunakan.

2. Melakukan pemerikasaan kerusakan perangkat IT hardware masih manual menggunakan kertas yang berisi tabel kerusakan - kerusakan perangkat dan saat terjadi trouble masih mahasiswa atau dosen tidak bisa komplain secara langsung harus membutuhkan watku yang cukup lama.

\section{Pemecahan Masalah}

Setelah mengamati dan meneliti dari beberapa permasalahan yang terjadi penulis mengusulkan pemecahan masalah yang dihadapi, yaitu :

Vol.2 No.2 - Agustus 2016 
1. Disaat ada laporan kerusakan perangkat IT hardaware pada kerusakan komputer lab bagian teknik menerima laporan tersebut langsung melalui sistem monitoring yang diusulkan.

2. Dosen atau mahasiswa dapat melakukan komplain secara langsung pada form keluhan yang tersedia pada sistem kerusakan komputer lab pada setiap kelas laboratorium.

\section{Rancangan Tampilan Sistem Yang Diusulkan}

a. Tampilan Halaman Menu Login

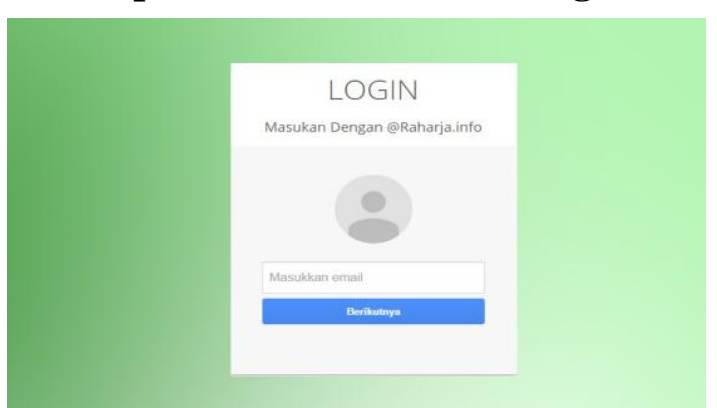

Gambar 4. Halaman Menu Login.

Halaman login merupakan tampilan menu yang pertama kaliakan tampil ketika user menjalankan sistem ini. Pada halaman ini user diminta untuk memasukkan username, password, dan hak akses sebagai apa, agar dapat mengakses halaman utama. Didalam sistem ini hanya meliki hak akses yaitu teknik atau asisten lab.

\section{b. Tampilan Halaman Home}

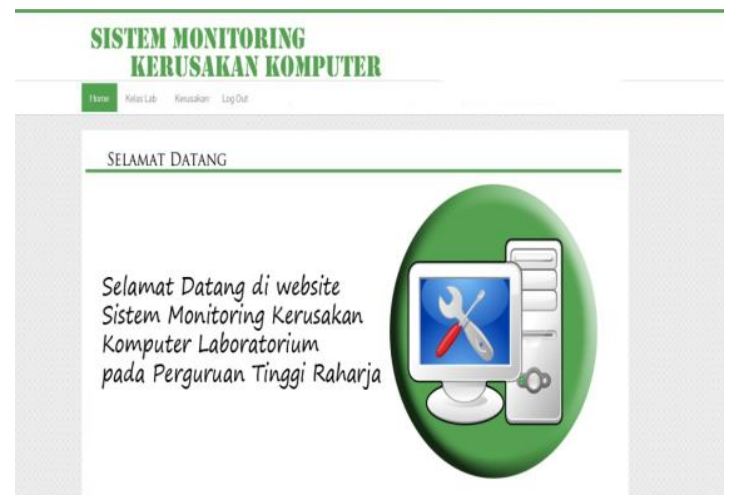

Gambar 4. Tampilan Home.

Halaman Home merupakan tampilan menu utama setelah user melakukan login pada menu login.

Vol.2 No.2 - Agustus 2016 


\section{c. Tampilan Halaman Menu Kelas Laboratorium}

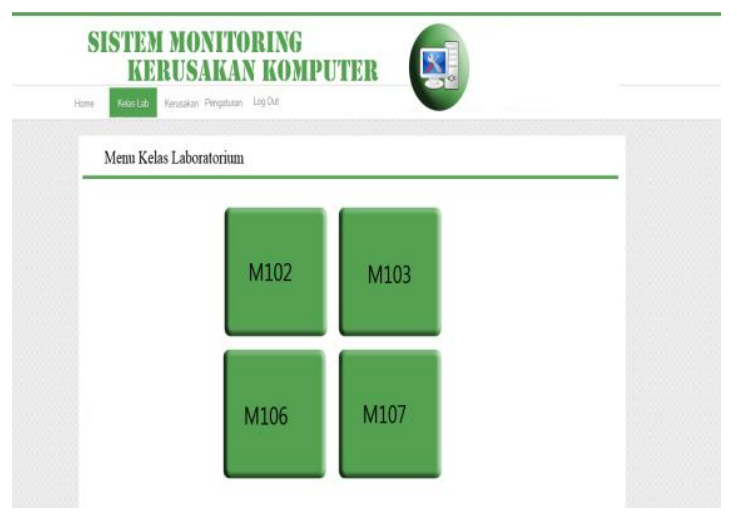

Gambar 5. Menu kelas Laboratorium.

Halaman Menu Kelas Laboratorium merupakan tampilan menu yang berisikan ruangan kelas laboratorium.

\section{d. Tampilan Halaman Info Kerusakan Keluhan}

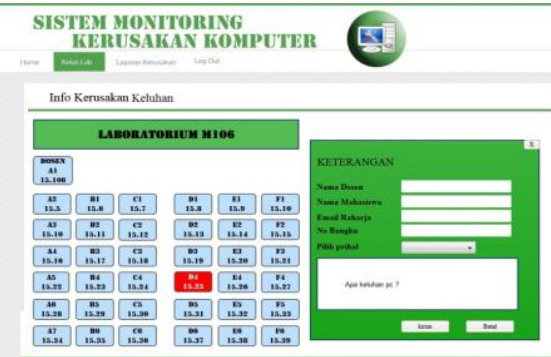

Gambar 6. Tampilan Info kerusakan keluhan.

Halaman keluhan merupakan dimana dosen dan mahasiswa disaat kelas lab terjadi kerusakan, dapat memberikan informasi atau keluhan kerusakan perangkat IT hardware pada rungan lab kepada bagian teknik.

\section{e. Tampilan Halaman Info Kerusakan}

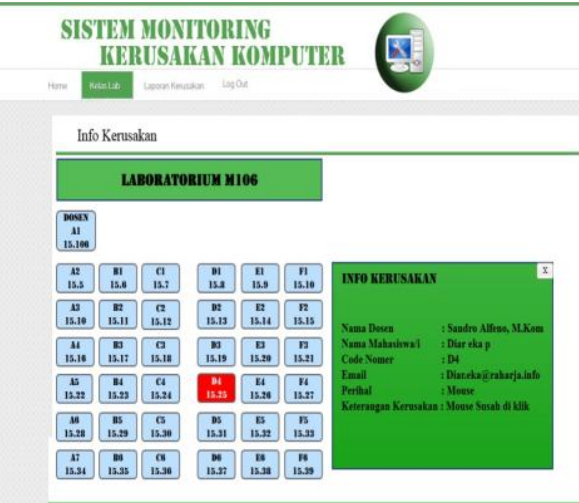

Gambar 7. Tampilan Info Kerusakan.

Vol.2 No.2 - Agustus 2016 
Halaman informasi keluhan merupakan dimana teknik menerima informasi keluhan trouble perangkat IT hardware pada rungan kelas yang diinformasikan oleh dosen atau mahasiswa melalui sistem monitoring kerusakan komputer lab.

\section{f. Tampilan Halaman Entri Kerusakan Komputer}

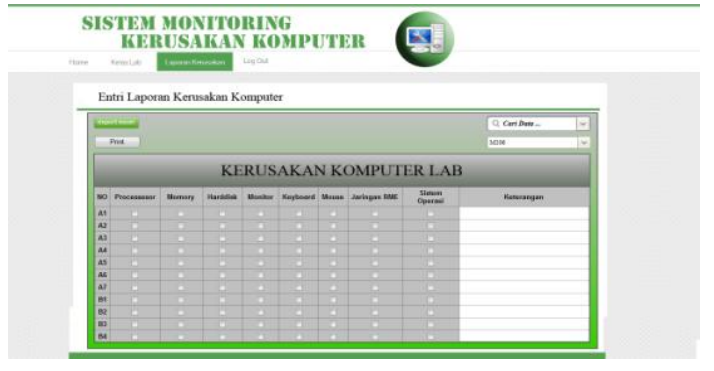

Gambar 8. Tampilan Entri laporan Kerusakan

Halaman laporan kerusakan komputer merupakan halaman untuk memasukan berbagai daftar laporan tentang kerusakan perangkat IT hardware pada laboratorium.

\section{Kesimpulan}

Berdasarkan uraian pada bab-bab sebelumnya, serta hasil analisa yang dilakukan oleh Penulis dalam sistem monitoring kerusakan komputer lab maka Penulis dapat memberikan kesimpulan sebagai berikut :

a. Prototype sistem monitoring keruskan komputer lab dapat membantu putugas asistem lab dalam pemeriksaan kerusakan komputer dalam sebuah sistem yang berbasis web dan dapat membantu petugas teknik mengesekusi komputer yang mengalami kerusakan yang diharapkan lebih efektif.

b. Pendeteksian perangkat IT hardware dengan mengunakan media LAN diharapkan dapat lebih efektif dalam hal penyampaikan laporan kerusakan perangkat IT hardware untuk laporan setiap bulan kepada kepala teknik.

c. Diharapkan dapat lebih akurat dari sistem sebelumnya yang masih mengunakan laporan manual dengan ceklist komputer lab yang masih menggunkan cara pengecekan komputer satu persatu.

\section{Daftar Pustaka}

[1] Adi Nugroho, "Analisa dan Perancangan Sistem Informasi dengan metologi".Yudistira.Bandung, 2008

[2] Dahria Muhammad, 2012 "Implementasi Backword Chaining Untuk Mengetahui Kerusakan Monitor Komputer" Jurnal ilmiah SAINTIKOM Vol. 11 / No.1 STMIK Triguna Dharma.

[3] Davis, Gordon B. “ Kerangka Dasar Sistem Informasi Manajemen”. 2008

Vol.2 No.2 - Agustus 2016 
[4] Hidayat, Rahmad, ST dan Minarini S. Si., M.T. 2013 "Rancang Bagun Aplikasi Sistem Pakar Untuk Kerusakan Komputer Dengan Metode Backward Cahaning". Institut Teknologi Padang. Padang: jurnal TEKNOIF Vol.1/no1, Edisi April 2013

[5] Junaidi , Tiara. Khanna, Yuliastrie. Nenden Dewi. "Sistem Pakar Monitoring Inventory Control Untuk Menghitung Harga Jual Efektif Dalam Meningkatkan Keuntungan". Yogyakarta: Universitas Ahmad Dahlan.

[6] Menurut Simarmata 2010. Konsep dasar Prototype Yogyakarta

[7] Nur Raina Novianti 2011 "Kontribusi pengelolaan laboratorium dan motivasi belajar siswa terhadap efektifitas pembelajaran" Jurnal Penelitian Pendidikan" Vol 12 No.2 Oktober 2011

[8] Sutabri, Tata. 2012. Konsep Sistem Informasi. Yogyakarta: Andi Offset.

[9] Yanuar Abid Badharudin, Aryanto Dwi. 2011. "Aplikasi sistem pakar untuk mendiagnosa kerusakan monitor CRT (Cathode Ray Tube)" pada JUITA ISSN:201869398 Vol Nomer 4. Purwokerto: Univesita Muhammadiyah.

Vol.2 No.2 - Agustus 2016 